\title{
Evolution of insecticide resistance and its mechanisms in Anopheles stephensi in the WHO Eastern Mediterranean Region
}

\author{
Ahmadali Enayati ${ }^{1} \mathbb{0}$, Ahmad Ali Hanafi-Bojd² ${ }^{2}$ Mohammad Mehdi Sedaghat ${ }^{2}$, Morteza Zaim²* \\ and Janet Hemingway ${ }^{3}$
}

\begin{abstract}
Background: While Iran is on the path to eliminating malaria, the disease with 4.9 million estimated cases and 9300 estimated deaths in 2018 remains a serious health problem in the World Health Organization (WHO) Eastern Mediterranean Region. Anopheles stephensi is the main malaria vector in Iran and its range extends from Iraq to western China. Recently, the vector invaded new territories in Sri Lanka and countries in the Horn of Africa. Insecticide resistance in An. stephensi is a potential issue in controlling the spread of this vector.
\end{abstract}

Methods: Data were collated from national and international databases, including PubMed, Google Scholar, Scopus, ScienceDirect, SID, and IranMedex using appropriate search terms.

Results: Indoor residual spaying (IRS) with DDT was piloted in Iran in 1945 and subsequently used in the malaria eradication programme. Resistance to DDT in An. stephensi was detected in Iran, Iraq, Pakistan, and Saudi Arabia in the late 1960s. Malathion was used for malaria control in Iran in 1967, then propoxur in 1978, followed by pirimiphosmethyl from 1992 to 1994. The pyrethroid insecticide lambda-cyhalothrin was used from 1994 to 2003 followed by deltamethrin IRS and long-lasting insecticidal nets (LLINs). Some of these insecticides with the same sequence were used in other malaria-endemic countries of the region. Pyrethroid resistance was detected in An. stephensi in Afghanistan in 2010, in 2011 in India and in 2012 in Iran. The newly invaded population of An. stephensi in Ethiopia was resistant to insecticides of all four major insecticide classes. Different mechanisms of insecticide resistance, including metabolic and insecticide target site insensitivity, have been developed in An. stephensi. Resistance to DDT was initially glutathione $\mathrm{S}$-transferase based. Target site knockdown resistance was later selected by pyrethroids. Esterases and altered acetylcholinesterase are the underlying cause of organophosphate resistance and cytochrome p450s were involved in pyrethroid metabolic resistance.

Conclusions: Anopheles stephensi is a major malaria vector in Iran and many countries in the region and beyond. The species is leading in terms of development of insecticide resistance as well as developing a variety of resistance mechanisms. Knowledge of the evolution of insecticide resistance and their underlying mechanisms, in particular, are important to Iran, considering the final steps the country is taking towards malaria elimination, but also to other countries in the region for their battle against malaria. This systematic review may also be of value to countries and territories newly invaded by this species, especially in the Horn of Africa, where the malaria situation is already dire.

\footnotetext{
*Correspondence: mortezazaim@gmail.com

2 Department of Medical Entomology and Vector Control, School of Public Health, Tehran University of Medical Sciences, Tehran, Iran

Full list of author information is available at the end of the article
}

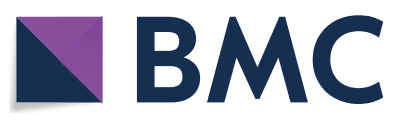

(c) The Author(s) 2020. This article is licensed under a Creative Commons Attribution 4.0 International License, which permits use, sharing, adaptation, distribution and reproduction in any medium or format, as long as you give appropriate credit to the original author(s) and the source, provide a link to the Creative Commons licence, and indicate if changes were made. The images or other third party material in this article are included in the article's Creative Commons licence, unless indicated otherwise in a credit line to the material. If material is not included in the article's Creative Commons licence and your intended use is not permitted by statutory regulation or exceeds the permitted use, you will need to obtain permission directly from the copyright holder. To view a copy of this licence, visit http://creativeco mmons.org/licenses/by/4.0/. The Creative Commons Public Domain Dedication waiver (http://creativecommons.org/publicdomain/ zero/1.0/) applies to the data made available in this article, unless otherwise stated in a credit line to the data. 
Keywords: Anopheles stephensi, Resistance, Mechanisms, Iran, Eastern Mediterranean Region

\section{Background}

Iran is on track to achieve malaria elimination, with zero indigenous cases in 2017 and 2018 [1]. National strategic planning is in place to eliminate the disease. In contrast, in the early $20^{\text {th }}$ Century, there were five million cases of malaria in a country of 18 million people [2, 3]. Now $1 \%$ of the 81 -million population live in malaria-endemic areas [1] compared with $75 \%$ in 1925 [3].

DDT was first used in Iran for malaria vector control in 1945 [2-4]. It was the insecticide of choice during the national malaria eradication campaign starting in 1956 following the Global Malaria Eradication Programme (GMEP) guidelines [2-7]. Insecticide resistance prompted a series of insecticide changes over time, from DDT to dieldrin, malathion, propoxur, pirimiphosmethyl, lambda-cyhalothrin, and deltamethrin to the present time [3, 8-20].

Iran was not alone in the battle against malaria. Almost all malaria-endemic countries outside sub-Saharan Africa embraced the GMEP using the main intervention of indoor residual spraying (IRS) [6, 7]. Resistance to several insecticides of all major classes has been reported in Anopheles stephensi in other countries of the WHO Eastern Mediterranean Region (EMR), including Saudi Arabia [21, 22], Iraq [23, 24], Afghanistan [25-28], and Pakistan $[29,30]$. Resistance to DDT, dieldrin, malathion, and recently pyrethroid insecticides, was reported from different states of India [31-41].

Involvement of several enzyme groups in insecticide resistance is evident in many insects, including mosquitoes [42-46]. Several mechanisms including metabolic and insecticide target site insensitivity are involved in insecticide resistance in An. stephensi from different countries, each of which has its own operational significance in vector control [26-28, 31, 33-36, 38, 39, 42, 47, 48].
Recently, An. stephensi expanded its distribution range into Sri Lanka and the Horn of Africa, where it has been detected in Djibouti, Ethiopia and Sudan [49-54]. The species in Ethiopia was highly resistant to DDT, malathion, pirimiphos-methyl, bendiocarb, propoxur, deltamethrin, and permethrin [54]. Resistance to insecticides was also detected in An. stephensi in Sri Lanka [55]. This expansion of the distribution range in Asia and especially in Africa is a cause for concern so that the WHO organized a technical consultation meeting to assess the situation in 2019 [52]. This evidence-based analysis of the literature on insecticide resistance in An. stephensi in Iran and the countries of the EMR, especially the countries and territories recently invaded by An. stephensi, is designed to inform national malaria programmes for appropriate deployment of vector control interventions and timely management of insecticide resistance in line with the WHO Global Plan for Insecticide Resistance Management (GPIRM) [56].

\section{Methods}

This is a systematic review of all literature and evidence available for insecticide resistance in An. stephensi.

\section{Inclusion criteria}

All studies on insecticide resistance performed on adults and larvae of An. stephensi from WHO EMR countries using WHO standard kits and procedures for mosquito susceptibility tests were included regardless of dates and language. Studies using filter papers impregnated with only WHO-recommended discriminating concentrations of insecticides for adult mosquitoes or WHO-discriminating concentration for larvae detailed in Table 1, were included in the review. Studies using laboratory-selected strains were included only where they reported the underlying resistance mechanisms. India and Ethiopia

Table 1 Susceptibility status ( $R$ resistant, $R C$ resistance to be confirmed, $S$ susceptible, NR no report) of Anopheles stephensi to selected insecticides in Iran (2020)

\begin{tabular}{|c|c|c|c|c|c|c|c|c|}
\hline \multirow[t]{2}{*}{ Province } & \multicolumn{2}{|c|}{ Organochlorines } & \multicolumn{2}{|c|}{ Organophosphates } & \multicolumn{2}{|c|}{ Carbamates } & \multicolumn{2}{|l|}{ Pyrethroids } \\
\hline & DDT $4 \%$ & Dieldrin $4 \%$ & Malathion 5\% & $\begin{array}{l}\text { Temephos } \\
0.25 \mathrm{mg} / \mathrm{l}\end{array}$ & $\begin{array}{l}\text { Propoxur } \\
0.1 \%\end{array}$ & $\begin{array}{l}\text { Bendiocarb } \\
0.1 \%\end{array}$ & $\begin{array}{l}\text { Lambdacyhalothrin } \\
0.05 \%\end{array}$ & $\begin{array}{l}\text { Deltamethrin } \\
0.05 \%\end{array}$ \\
\hline Fars $^{\mathrm{a}}$ & $\mathrm{R}$ & $\mathrm{R}$ & $\mathrm{R}$ & $N R$ & S & $N R$ & $N R$ & NR \\
\hline Hormozgan & $R^{b}$ & $\mathrm{R}$ & S & S & RC & $\mathrm{R}$ & $\mathrm{R}$ & $\mathrm{RC}$ \\
\hline Kerman & $\mathrm{RC}$ & NR & $S$ & S & S & $\mathrm{R}$ & S & S \\
\hline Sistan and Baluchestan & $\mathrm{R}$ & $S$ & $\mathrm{RC}$ & $N R$ & $\mathrm{R}$ & $\mathrm{RC}$ & $\mathrm{R}$ & $\mathrm{R}$ \\
\hline
\end{tabular}

a As malaria has long been eliminated from this province, the susceptibility bioassays are rather old

b There is only one outlier study to this generalization which needs confirmation 
are not WHO member states of the EMR but studies from the former are included as there are several reports in the literature on the resistance of the species to different insecticides and its underlying mechanisms, and the latter is included as the insecticides susceptibility status in An. stephensi in countries newly invaded by the species is important.

\section{Exclusion criteria}

Studies and experiments using insecticides and concentrations or test kits other than those approved by WHO, including those using plant extracts, dose-response bioassays, bioassays performed on nets and residual bioassays, were excluded from this study.

\section{Search strategy, study selection, data extraction, and synthesis}

The search period was from 1 January, 1925 to 10 March, 2020. The following databases were searched for relevant studies using appropriate search terms and strategy: PubMed, Google Scholar, Scopus, ScienceDirect, SID, and IranMedex. Relevant conference proceedings were checked and the reference lists of all included studies identified by the above methods were also hand searched.

The search results were primarily screened based on the title and abstract followed by a second round of screening through the full text to select relevant studies for inclusion in the review. Blank tables were designed in Microsoft Excel and used to extract the relevant data from the included studies. The extracted data were used to build a chronological history of insecticide resistance and its underlying mechanisms in An. stephensi. The insecticide resistance data were used to plot separate maps indicating the distribution of resistance to insecticides. WHO criteria and classification for insecticide resistance [57] were considered for mapping. All maps were prepared in ArcGIS 10.5 at the district level for Iran and province/state level for the region. Shape files of Iran were provided by the National Cartography Centre, while the shape files for the region were downloaded from the Natural Earth website (www.naturalearthdata.com).

\section{Results}

After its first application as indoor residual spraying (IRS) for malaria control in Iran in 1945 [2, 3, 6, 7], DDT was used until 1957 when An. stephensi became resistant to it [8] followed by dieldrin use and development of resistance in 1959-1960 [9-12]. In later years susceptibility to DDT and dieldrin decreased further in the 1970s $[11,15,58]$. Susceptibility to these insecticides gradually rose to the final years of the Millennium [19, 20, 59, 60]. Over the years, DDT resistance persisted but that of dieldrin decreased more rapidly changing its susceptibility status to tolerance [61], and later to complete susceptibility [62-64]. However, from 2010, susceptibility of $A n$. stephensi to DDT and dieldrin decreased, may be due to the emergence of resistance to pyrethroid insecticides [65-71]. The susceptibility status of An. stephensi to organochlorine insecticides in different provinces of Iran is summarized in Table 1 and mapped in Fig. 1.

Due to the double resistance of An. stephensi to DDT and dieldrin, malathion IRS was used in malaria vector control in Iran since 1968 [14]. Susceptibility bioassays in 1975 showed that the species was susceptible to malathion with a mortality of $99 \%[11,15]$. However, the species developed resistance to malathion in 1976 [17] and remained so for some years [58]. Regardless of a couple of instances of mortality of less than 95\% in 2011 [64] and $90 \%$ in 2015 [72], the species proved to be susceptible to malathion-discriminating concentration since 1982 in its entire range in southern Iran $[19,59-62,65,66,68,69$, 71]. Interestingly, resistance to malathion in adult An. stephensi did not decrease the susceptibility of its larvae to temephos within the same organophosphate (OPs) class [73]. Several susceptibility bioassays on An. stephensi larvae to temephos showed complete susceptibility [60, 61, 68, 74, 75]. The susceptibility status of An. stephensi to OPs in different provinces of Iran is summarized in Table 1 and mapped in Fig. 1.

Since 1978, propoxur was used as IRS for malaria vector control in Iran $[18,19]$. Propoxur bioassays revealed complete susceptibility in later years $[19,58]$. Although subsequently the susceptibility status to propoxur and bendiocarb changed to tolerance $[20,72,75]$, susceptibility to propoxur is restored while resistance to bendiocarb developed in the species in recent years [59-61, 64, 68, 69, 76]. The susceptibility status of An. stephensi to carbamate insecticides in different provinces of Iran is summarized in Table 1 and mapped in Fig. 1.

Pirimiphos-methyl replaced propoxur in 1991 until it was replaced with lambda-cyhalothrin plus propoxur in 1994 [19, 20]. Since 2003, IRS continued using only deltamethrin and lambda-cyhalothrin until 2011. Since 2012, deltamethrin plus bendiocarb were used in an alternative manner for pyrethroid insecticide resistance management [3]. Follow-up bioassays from 2004 to 2010 revealed complete susceptibility to these insecticides in An. stephensi from its entire range in southern areas of Iran $[59-64,66]$. The first sign of reduced susceptibility to deltamethrin with $97 \%$ mortality emerged in 2010 in an area in the south of Iran [77], followed by the development of resistance to lambda-cyhalothrin and resistance to be confirmed to deltamethrin [67, 68]. Despite the results of a couple of studies in 2014 and 2015 showing complete susceptibility of An. stephensi to deltamethrin $[69,72]$, decreased susceptibility to pyrethroid 

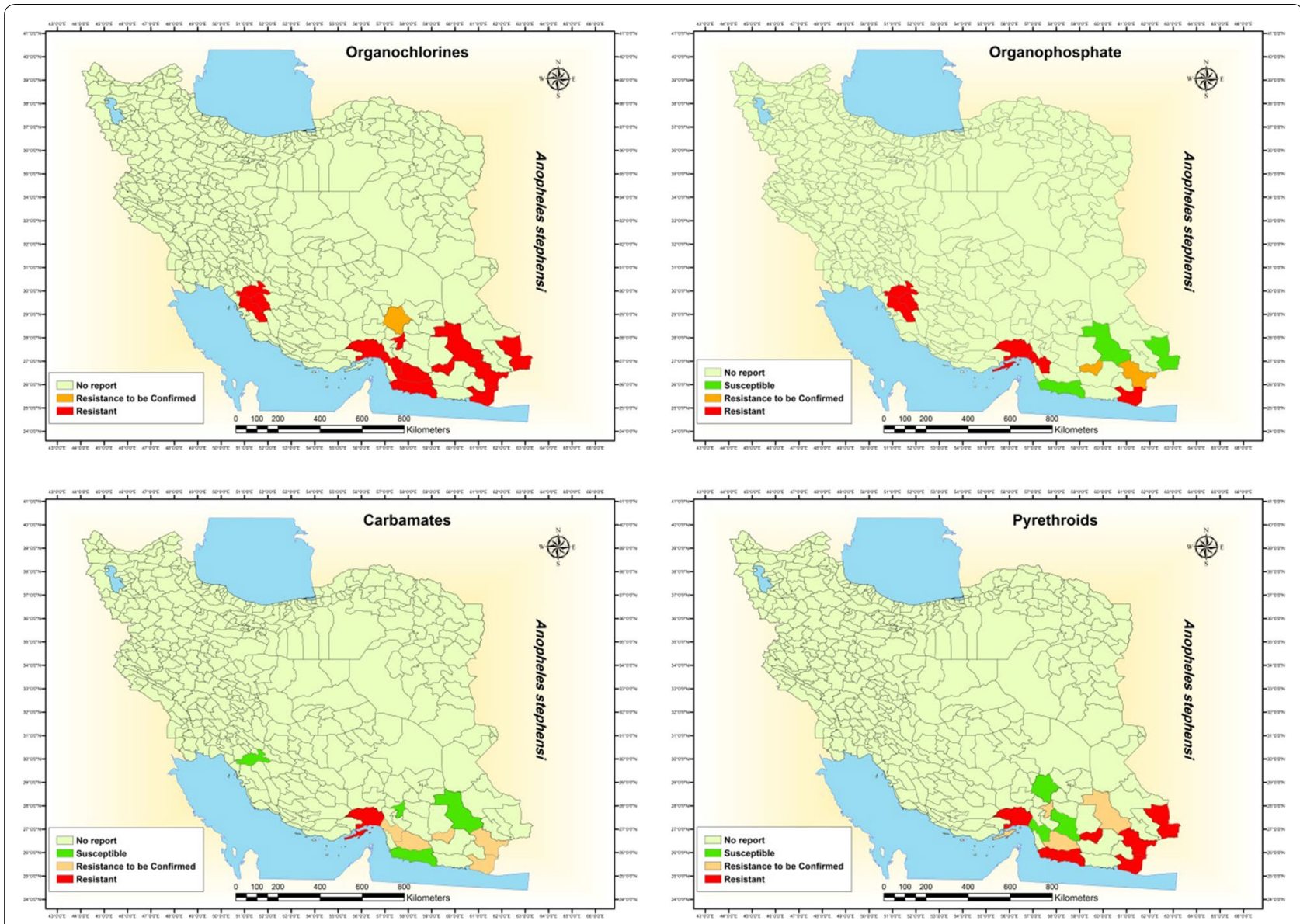

Fig. 1 Insecticide resistance status of An. stephensi to different insecticides at district level in Iran

insecticides were observed in later years [70-72, 75, 78]. In included studies, susceptibility of An. stephensi to many pyrethroid insecticides were determined, however, only the susceptibility status of An. stephensi to deltamethrin and lambda-cyhalothrin in different provinces of Iran is summarized in Table 1 and mapped in Fig. 1.

\section{Insecticide resistance in Anopheles stephensi in other WHO/ EMR countries, plus India, Sri Lanka and Ethiopia}

In Afghanistan, there was evidence of resistance in $A n$. stephensi to DDT, malathion, bendiocarb, deltamethrin, and permethrin in 2011 [25]. Although there are data supporting the susceptibility of the species to bendiocarb and permethrin in some provinces, resistance or resistance to be confirmed has been detected in An. stephensi to aforementioned insecticides in most provinces of Afghanistan in the follow-up studies performed in 2014, 2016 and 2017 [26-28, 79]. Anopheles stephensi from Lahore, Pakistan was resistant to DDT and malathion [80]. The species proved to be resistant to DDT, malathion, deltamethrin and lambda-cyhalothrin in South
Punjab [81]. In another study in Punjab Province, the species was found to be significantly resistant to DDT, dieldrin and malathion while being susceptible to permethrin, deltamethrin and fenitrothion [29]. In a follow-up study in Punjab Province, the species showed resistance to lambda-cyhalothrin, cyfluthrin and cypermethrin [30]. Therefore, An. stephensi in Pakistan is resistant to DDT, dieldrin, malathion, and pyrethroid insecticides [79, 82].

Not much is known about the susceptibility status of An. stephensi from Iraq. In studies in 1957 and 1980, the species was resistant to DDT, dieldrin and malathion in the country [23, 80]. In India, An. stephensi is resistant to DDT in Delhi, Gujarat, Rajasthan, Kerala and Madhya Pradesh whereas it is susceptible to DDT in Karnataka. The species is resistant to malathion in Delhi, West Bengal, Goa, Gujarat, Rajasthan, and Karnataka, susceptible in Kerala and Maharashtra, and resistant to be confirmed in Madhya Pradesh. To deltamethrin, the species is resistant in Karnataka, resistant to be confirmed in Gujarat but susceptible in Kerala, Delhi, Uttar Pradesh, West Bengal and Rajasthan [31-33, 36, 39-41, 79, 82, 83]. In a recent 
study in Sri Lanka, the species is resistant to DDT, malathion and deltamethrin [55].

In Ethiopia, An. stephensi was resistant to insecticides of all major classes. Mortality after exposure to the discriminating concentrations of DDT, malathion, pirimiphos-methyl, bendiocarb, propoxur, permethrin and deltamethrin were $32 \%, 32 \%, 14 \%, 23 \%, 21 \%, 53 \%$ and $67 \%$, respectively, revealing relatively high resistance to all those insecticides [54]. The susceptibility status of $A n$. stephensi to different insecticides in different states/provinces of different countries is summarized in Table 2 and mapped in Fig. 2.

\section{Mechanisms of insecticide resistance in Anopheles stephensi}

Synergist bioassays on the DDT and permethrinresistant laboratory strains of An. stephensi from Iran using dichloromethyl benzhydrol (DMC) and piperonyl butoxide (PBO) denoted the involvement of glutathione S-transferases (GSTs) and cytochrome p450s rather than target site insensitivity [84-86]. A genomic study on DDT-resistant strain of An. stephensi showed that GSTe2 may be an underlying resistance mechanism in DDT resistance in Iranian An. stephensi [62].

The most important mechanisms of resistance to temephos in An. stephensi larvae were $\alpha$-esterases, GSTs and AChE insensitive to propoxur rather than being due to mutations in ace1 gene [87]. In a follow-up study, it was revealed that the microbiota of the mosquitoes may play a role in their susceptibility status to insecticides as the enzymes involved in resistance of An. stephensi to temephos were dramatically reduced in resistant strain when treated with antibiotic [88].

Combination of deltamethrin and PBO applied as IRS resulted in higher mortality in An. stephensi adults compared with deltamethrin alone in a semi-field trial in southern Iran. This finding not only reveals the involvement of cytochrome p450s, at least in part, in pyrethroid insecticides resistance, but also shows the benefit of adding $\mathrm{PBO}$ to pyrethroid insecticides for malaria vector control to manage insecticide resistance in the field [78]. Involvement of GSTs, esterases and cytochrome p450s in DDT and pyrethroid insecticide resistance was also revealed in a study involving An. stephensi adults that underwent selection for DDT and cyfluthrin [89].

In a study on the mechanisms of insecticide resistance in An. stephensi in Afghanistan, it was revealed that $k d r$ mutations were partially involved in the resistance to pyrethroids as well as DDT, however, the frequency of the $k d r$ alleles identified in this study did not explain the whole of the resistance phenotype in An. stephensi in eastern Afghanistan, suggestive of involvement of biochemical mechanisms [26]. A follow-up study in Afghanistan revealed that reported resistance to pyrethroid and organophosphorus insecticides, and tolerance to bendiocarb are likely to be caused by a range of metabolic

Table 2 Susceptibility status of An. stephensi from different states/province of countries in EMR plus India and Ethiopia

\begin{tabular}{|c|c|c|c|c|c|c|}
\hline Country & State & OC & OP & $C$ & PY & Reference \\
\hline Afghanistan & Nangarhar & $\mathrm{R}$ & $\mathrm{R}$ & $\mathrm{R}$ & $\mathrm{RC}$ & {$[26-28]$} \\
\hline Afghanistan & Ghazni & $\mathrm{R}$ & $\mathrm{R}$ & $\mathrm{R}$ & $\mathrm{R}$ & {$[26-28]$} \\
\hline Afghanistan & Kunar & $\mathrm{R}$ & S & S & $\mathrm{R}$ & {$[26-28]$} \\
\hline Afghanistan & Laghman & $\mathrm{R}$ & $\mathrm{R}$ & $\mathrm{R}$ & $\mathrm{RC}$ & {$[26-28]$} \\
\hline Pakistan & Punjab & $\mathrm{R}$ & $\mathrm{R}$ & $\mathrm{R}$ & $\mathrm{R}, \mathrm{RC}, \mathrm{S}$ & {$[29,30,80,82]$} \\
\hline India & Delhi & $\mathrm{R}$ & $\mathrm{R}$ & NR & S & {$[31-33,36,39-41,82,83]$} \\
\hline India & Gujarat & $\mathrm{R}$ & $\mathrm{R}$ & NR & $\mathrm{RC}$ & {$[31-33,36,39-41,82,83]$} \\
\hline India & Rajasthan & $\mathrm{R}$ & $\mathrm{R}$ & NR & S & {$[31-33,36,39-41,82,83]$} \\
\hline India & Kerala & $\mathrm{R}$ & S & NR & $\mathrm{S}$ & {$[31-33,36,39-41,82,83]$} \\
\hline India & Madhya Pradesh & $\mathrm{R}$ & $\mathrm{RC}$ & NR & NR & {$[31-33,36,39-41,82,83]$} \\
\hline India & Karnataka & S & $\mathrm{R}$ & NR & $\mathrm{R}$ & {$[31-33,36,39-41,82,83]$} \\
\hline India & West Bengal & NR & $R$ & NR & $S$ & {$[31-33,36,39-41,82,83]$} \\
\hline India & Goa & NR & $\mathrm{R}$ & NR & NR & {$[31-33,36,39-41,82,83]$} \\
\hline India & Maharashtra & NR & S & NR & NR & {$[31-33,36,39-41,82,83]$} \\
\hline India & Uttar Pradesh & NR & NR & NR & S & {$[31-33,36,39-41,82,83]$} \\
\hline Sri Lanka & Jafna & $\mathrm{R}$ & $\mathrm{R}$ & NT & $\mathrm{R}$ & {$[55]$} \\
\hline Iraq & Basrah & $\mathrm{R}$ & NR & NR & NR & {$[23]$} \\
\hline Saudi Arabia & Qatif & $\mathrm{R}$ & NR & NR & NR & {$[21]$} \\
\hline Ethiopia & Regional State & $\mathrm{R}$ & $\mathrm{R}$ & $\mathrm{R}$ & $\mathrm{R}$ & {$[54]$} \\
\hline
\end{tabular}

$O$ : organochlorine, $O P$ organophosphates, $C$ carbamate, $P Y$ pyrethroid, $R$ resistant, $R C$ resistance to be confirmed, $S$ susceptible, $N R$ no repot 

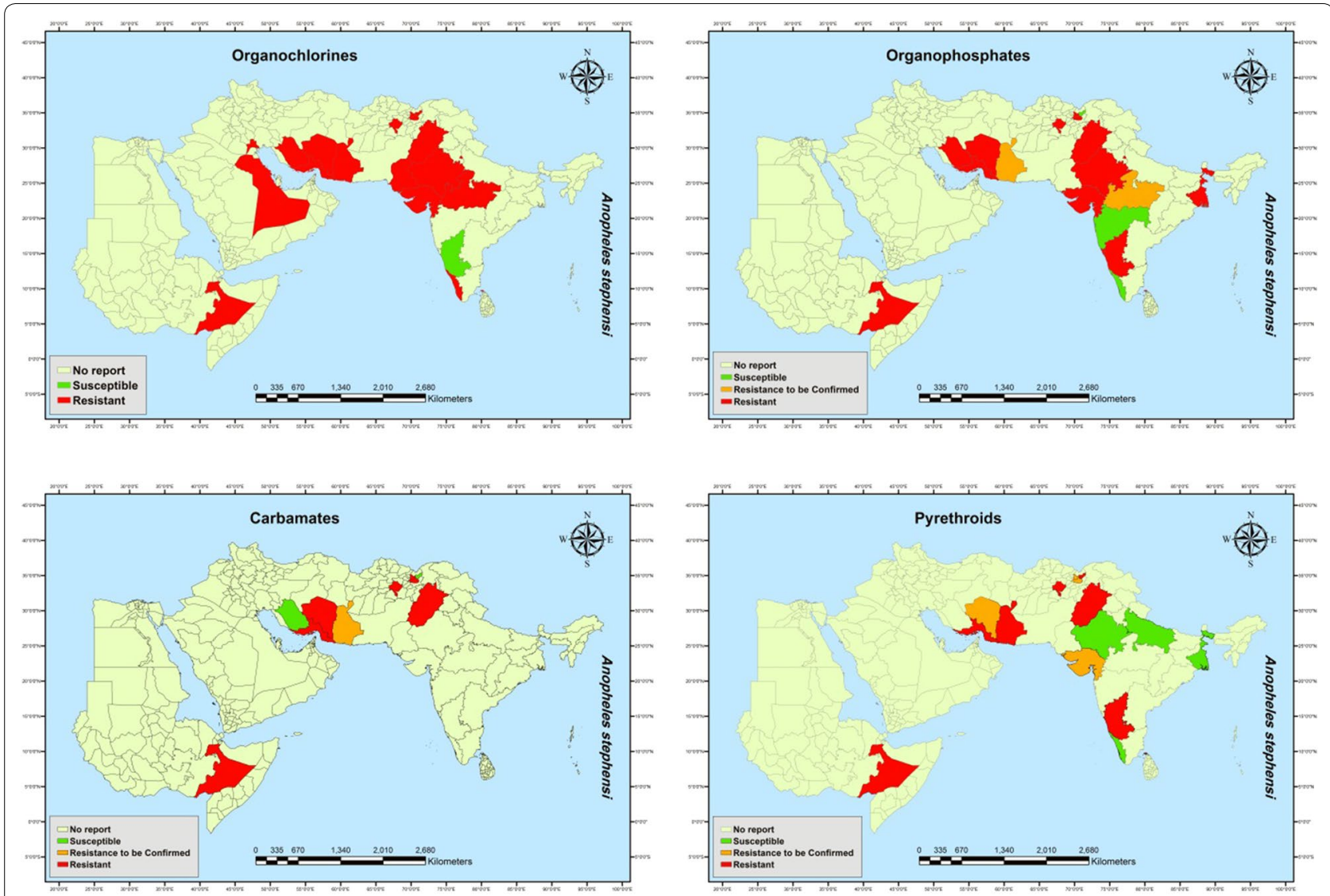

Fig. 2 Susceptibility ststus of An. stephensi to different insecticide groups in EMR

mechanisms, including esterases, cytochrome p450s and GSTs combined with insensitivity in AChE [27]. In another study in eastern Afghanistan, a combination of metabolic mechanisms and increased frequency of $k d r$ alleles in the mosquito were blamed for elevated resistance [28]. In Pakistan, esterases are involved in malathion resistance in An. stephensi $[90,91]$. In India, the involvement of different enzyme groups including esterases, GSTs and cytochrome p450s as well as site insensitivity mechanism of $k d r$ west and east alleles was revealed [31, 33-36, 38, 39, 47, 48]. The site insensitivity resistance mechanisms in An. stephensi from Ethiopia was studied but no $k d r$ or ace1 traits were detected, this may imply the involvement of metabolic mechanisms [54].

\section{Discussion}

Although globally continuous progress is being made in malaria control over the decades, the disease is by far the most important killer in the world [1]. Numerous different strategies and measures have been used to combat malaria, however, insecticide use is pivotal to its vector control and to the interruption of transmission [92]. Continued use of insecticides results in selection for insecticide resistance in vectors of diseases, therefore, continuous monitoring of insecticide resistance and its distribution, mechanisms and management are crucially important for sustainable malaria vector control. The WHO has always urged member states to build adequate capacity and capability for routine monitoring and evaluation of insecticide resistance in malaria vectors through developing plan of action [56, 93-97]. This is not only important for countries that are in the 'control strategy' phase, but is of paramount importance for those in the 'elimination' and even 'post-elimination phase' [97].

The premature development of DDT resistance in Iran in 1957 was probably because of the earlier use of DDT in malaria control in Iran starting in 1945, way before its widespread use during the eradication programme in 1956 [3]. It is interesting to note that in later years even with the cessation of DDT use, it took much longer time for the species to increase its susceptibility to DDT in comparison to the trend of regaining susceptibility to malathion. One reason for that might stem from the fact that DDT resistance is a recessive trait whereas resistance to malathion is more like semi-dominant [80]. Susceptibility to DDT decreased again after 2010 which coincided 
with the gradual emergence of pyrethroid insecticide resistance and may be due to common metabolic resistance mechanism.

Emergence of pyrethroid insecticide resistance itself in An. stephensi in Iran is a cause for concern for malaria control and a potential threat to the malaria elimination programme of the country. Insecticide resistance management strategies are recommended to keep the remaining active ingredients in the arsenal of public health. In recent years An. stephensi from Iran developed resistance to bendiocarb, an insecticide used in alternation with pyrethroids to manage insecticide resistance. Resistance to malathion detected in 1976 [11] did not last for long and also its cross resistance spectrum did not include temephos [73]. Serious resistance to propoxur was never detected in An. stephensi from Iran and the reason for its replacement with pyrethroid insecticides seems to be more of procurement, cost or pre-emptive insecticide resistance management issues.

The speed of resistance development is dependent on the intrinsic (genetic) and extrinsic (selection pressure) factors. While DDT resistance developed relatively fast in some species, e.g., An. stephensi, its development in some other species, e.g., Anopheles funestus in South Africa where IRS with DDT started in 1946 was rather slow [98]. In 1996, DDT was replaced with pyrethroid [99], which had to be reversed due to the detection of monooxygenase-based pyrethroid insecticide resistance with no cross-resistance to DDT in An. funestus in KwaZulu-Natal Province in 2000 [98].

The development of resistance to different insecticides in An. stephensi is usually state- or province-specific within a country as other factors, e.g., differential selection pressure and use of insecticide in agriculture are different. For example An. stephensi in Kunar Province in Afghanistan is susceptible to bendiocarb so IRS using this insecticide is prescribed for malaria control in this province. Cytochrome p450, involved in pyrethroid insecticide resistance, is the highest in Laghman and Nangarhar Provinces where PBO-nets can be deployed [28]. The same situation is true in Iran as resistance to certain insecticides is province-specific (Table 1). In South Africa, in part of the malarious areas, DDT IRS is used for malaria vector control whereas in other states, different insecticides are being used [1,98].

Anopheles stephensi has recently invaded new territories and countries in Asia and the Horn of Africa [4954]. In this invasion, the mosquito takes its insecticide resistance heritage with it as in studies on the insecticide resistance in An. stephensi in Ethiopia and Sri Lanka, the species was resistant to major groups of insecticides [54, 55]. Therefore it might be worthwhile to identify the origin of the mosquito should it appear in a new territory.
The WHO urges member states to routinely monitor insecticide resistance, its intensity and underlying mechanisms by establishing sentinel sites with adequate temporal and spatial coverage [97]. National plans of action for insecticide resistance monitoring and management are recommended to encompass all related issues. By reviewing the insecticide resistance monitoring data from countries in the region, it was revealed that these recommendations are not fully implemented. To be more specific, in some provinces/states with ongoing malaria transmission, the susceptibility bioassay data are either old or even non existent, performed sub-standardly; in provinces/states with cleared up foci, monitoring insecticide susceptibility is grossly ignored whereas instead, it should be planned and performed, at least with a longer intervals, especially in areas with higher receptivity where malaria may be re-introduced. Another operational issue is the confirmation of resistance when it is considered 'resistance to be confirmed. Care must be taken not to treat this as an independent category of insecticide resistance status, but based on the WHO recommendations, additional tests must be performed to confirm the susceptibility status, an operation mostly forgotten. Determination of the intensity of resistance using $5 \times$ and $10 \times$ insecticide-treated papers is also emphasized to guide the programmes to choose the right insecticides [97]. Creating consortia of programmes, universities and research institutes for information and knowledge exchange between member states is encouraged to build the capacity of the region to adequately implement WHO recommendations regarding insecticide resistance monitoring and management.

DDT resistance in Iran and many other countries is primarily GST-related $[43,62,84-86,89]$. On the other hand, GSTs may be involved secondarily in pyrethroid insecticide resistance in some insects [46, 100]. Therefore, wherever resistance to DDT is present, it means that GSTs levels may still be high, so care must be taken if pyrethroid insecticides are going to be used for vector control. Esterases overexpressed by upregulation, gene amplification as well as enhanced metabolic property $[34,90,91,101,102]$ are involved mainly in organophosphorus and secondarily in carbamate and pyrethroid insecticides resistance. The involvement of esterases in insecticide resistance in An. stephensi from Iran, Afghanistan, India, and Pakistan is documented in several papers $[34,36,47,87,89,90,102,103]$. The rather wide spectrum of impact of esterase-based insecticide resistance is of important operational implication as it defines the cross-resistance spectrum. Cytochrome $\mathrm{p} 450$ is also of high importance in conferring insecticide resistance primarily to pyrethroid insecticides and to a lesser extent to DDT, OPs and propoxur in many insect groups $[44,45]$. 
Pyrethroid insecticide resistance in An. stephensi from Iran [78, 84-87], Afghanistan [27, 28] and India [34, 36] is in part due to cytochrome p450s. The involvement of $\mathrm{p} 450 \mathrm{~s}$ especially in pyrethroid insecticide resistance is of high operational implication and that is why WHO urges the malaria programmes to identify the involvement of cytochrome $\mathrm{p} 450 \mathrm{~s}$ in pyrethroid insecticide resistance using PBO-bioassay [97] to pave the way for possible $\mathrm{PBO}$ nets distribution. In such places IRS using pyrethroid insecticides plus PBO may also be feasible [78].

There are two types of $k d r$ alleles in Anopheles mosquitoes, i.e., $k d r$ west $[33,39,103]$ and $k d r$ east $[26,104]$. However, there is a slight difference in those two alleles in terms of conferring resistance to DDT and pyrethroids $[28,105]$. Therefore, not only it is important to identify the $k d r$ alleles and its frequency in the mosquito populations under investigation, but their differential impact on phenotypic resistance should also be considered when planning for vector control interventions. The first report of $k d r$ allele in An. stephensi was in the DUB-R laboratory strain [103]. Years later, several other studies detected $k d r$ west and east mutations in An. stephensi in India [31, 38, 39, 48, 106] and Afghanistan [26-28]. The presence of $k d r$ genotypes itself in low frequency may not jeopardize the effectiveness of pyrethroid insecticides especially in the form of LLINs [107-112]. However, if the trait is in high frequency and especially in combination with metabolic mechanisms, it may then impact the effectiveness of pyrethroid insecticides for malaria vector control as shown in a systematic review with meta-analysis [113]. This phenomenon again emphasizes the operational value of entomological surveillance especially monitoring insecticide resistance and its underlying mechanisms when planning malaria control.

Another important site insensitivity mechanism related to OPs and carbamates resistance is altered acetylcholine esterase $(\mathrm{aAChE})$. A population is considered having phenotypic aAChE type mechanism if the frequency of the trait in the population is more than 60\% [114]. Resistance to different OPs and carbamate insecticides in An. stephensi in Iran $[87,115]$ and Afghanistan $[27,28]$ can be traced back to aAChE. Therefore, the frequency of aAChE should be determined in order to guide the national malaria programme to choose the right insecticide for vector control.

In the face of insecticide resistance, attempts should be made to preserve the shelf life of public health pesticides two fold: first using insecticide resistance management strategies as well as through intersectoral collaboration, notably with agriculture sector as there are voluminous amounts of literature confirming the relationship between pesticide used in agriculture and emergence of insecticide resistance in disease vectors
[95, 116-120]. The other fold being research and development for production of alternative insecticides or formulations for malaria vector control in the face of insecticide resistance especially to pyrethroids as they are only approved chemicals to be used in LLINs construction, several of these new molecules or formulations are now in the pipe line [73, 78, 121-127].

\section{Conclusions}

Anopheles stephensi is an important, mostly urban, malaria vector in a wide range from Iraq to West China. In recent years, the species expanded its range to Sri Lanka and the Horn of Africa to Djibouti, Ethiopia and Sudan. The species is a leading malaria vector in terms of developing insecticide resistance. Since the development of DDT resistance in this vector in 1957 in Iran and in other countries in the region, voluminous amounts of literature have been produced on insecticide resistance in this species in EMR countries as well as in India. The species is now resistant to all major groups of insecticides with a different range of metabolic and site insensitivity mechanisms. As the countries of the range of distribution of this species, including the newly invaded ones, are in constant battle against malaria, continuous monitoring of insecticide resistance, its intensity and underlying mechanisms are essential to make evidence-based decisions when it comes to choosing vector control interventions. Also as insecticide resistance in An. stephensi is widespread, research and development on new formulations and molecules are essential to keep fighting malaria in countries of its range.

\section{Implication for practice}

Monitoring susceptibility status of An. stephensi to insecticides is not routinely performed in sentinel sites and with adequate temporal and spatial coverage. This gap can harm malaria programmes in member states when it comes to decision-making for vector control in control, elimination and even post-elimination scenarios. The results of this review are important to be considered and implemented into practice by the national malaria programme, as insecticide resistance management is essential to choose appropriate insecticide for malaria vector control, while moving to the final steps of malaria elimination in Iran. The same is true for countries engaged in battle against $A n$. stephensi for long time now or those countries and territories newly invaded by the species. 


\section{Implication for research}

Undertaking more research to elucidate the details of biochemical and molecular biology of the underlying mechanisms for insecticide resistance in An. stephensi in all countries of its range is highly encouraged. The results of research are crucial to keep the tools for vector control working to the final steps of malaria elimination in Iran and successful malaria vector control elsewhere. Research and development to produce lead molecules or new formulations is strongly recommended because of insecticide resistance, and because among other reasons, the number of available public health pesticides is limited.

\section{Abbreviations}

aAChE: altered acetylcholine esterase; AChE: acetylcholine esterase; DDT: dichlorodiphenyltrichloroethane; DMC: dichloromethyl benzhydrol; EMR: Eastern Mediterranean Region; GMEP: Global Malaria Eradication Program; GST: glutathione-S-transferases; IRS: Indoor Residual Spraying; Kdr: knockdown resistance; LLIN: long-lasting insecticidal nets; OPs: organophosphates; PBO: piperonyl butoxide; WHO: World Health Organization.

\section{Acknowledgements}

The authors would like to acknowledge the efforts made by Dr. F. Nikpour and Ms. SZ Parkhideh for their assistance in retrieving and arranging the references. We also would like to extend our gratitude to Dr. G. Zamani and Dr. S. Al-Eryani from $\mathrm{WHO}$ /EMRO for encouraging the team to undertake this task.

\section{Authors' contributions}

AE extracted the data and drafted the manuscript, AAHB helped extracting the data and drew the maps, MZ, MMS and $\mathrm{JH}$ were involved in the conception of the study and critically appraised the manuscript. All authors read and approved the final manuscript.

\section{Funding}

The study did not receive any specific funding.

\section{Availability of data and materials}

All data generated or analyzed during this study are included in this published article.

\section{Ethics approval and consent to participate}

Not applicable.

\section{Consent for publication}

All authors have read the manuscript and consented for its publication.

\section{Competing interests}

The authors declare that they have no competing interests.

\section{Author details}

1 Department of Medical Entomology and Vector Control, School of Public Health and Health Sciences Research Center, Mazandaran University of Medical Sciences, Sari, Iran. ${ }^{2}$ Department of Medical Entomology and Vector Control, School of Public Health, Tehran University of Medical Sciences, Tehran, Iran. ${ }^{3}$ Liverpool School of Tropical Medicine, Liverpool, UK.

Received: 1 May 2020 Accepted: 13 July 2020

Published online: 17 July 2020

\section{References}

1. World Health Organization. World malaria report 2019. Geneva: World Health Organization; 2019. p. 232.
2. Edrissian GH. Malaria history and status in Iran. J Sch Public Health Inst Public Health Res. 2003;1:50-61.

3. Schapira A, Zaim M, Raeisi A, Ranjbar M, Kolifarhood G, Nikpour F, et al. History of the successful struggle against malaria in the Islamic Republic of Iran. Tehran: Neekpey; 2018.

4. Azizi MH, Bahadori M. Brief historical perspectives of malaria in Iran. Arch Iran Med. 2013:16:131-5.

5. Zahar A. Review of the ecology of malaria vectors in the WHO Eastern Mediterranean Region. Bull World Health Organ. 1974:50:427-40.

6. Feachem RG, Phillips AA, Targett G. Shrinking the malaria map: a prospectus on malaria elimination. California: The Global Health Group, University of California; 2009.

7. Enayati A, Hemingway J. Malaria management: past, present, and future. Ann Rev Ent. 2010;55:569-91.

8. Mofidi C, Samimi B, Eshghi N, Ghiassedin M. Further studies of anopheline susceptibility to insecticides in Iran; results of Busvinc and Nash method. Inst Parasit Malariol. 1958;585:1-7.

9. Mofidi C, Samimi B. Resistance of Anopheles stephensi to dieldrin. Inst Parasit Malariol. 1960;650:3-4.

10. Carmichael AG, Motabar M, Sundararaman S, Rowhani F, Golestani J. Entomological evaluation of OMS-33 (0-isopropoxyphenyl methylcarbamate) in a stage $\mathrm{VI}$ operational field trial in Iran. WHONBC. 1968;105:1-34

11. Manouchehri A, Javadian E, Eshighy N, Motabar M. Ecology of Anopheles stephensi Liston in southern Iran. Trop Geogr Med. 1976;28:228-32.

12. Golestani J, Motabar M. Field experiment with the use of gamma$\mathrm{BHC}$ for the control of DLN and DDT resistant Anopheles stephensi mysorensis in the Khesht Area, Kazeroun, South of Iran. Acta Med Iran. 1971:14:111-29.

13. Motabar M, Eshghy N. Field trial of Sumithion (OMS 43) in the Mamasani area, southern Iran, August-December, 1972. Ent Med Parasitol. 1974;12:15-8

14. Manouchehri A, Shahgudian E, Kargar S, Ghiassedin M. A largescale malathion trial in the Bandar Abbas area. Iran J Public Health. 1972:1:60-8.

15. Eshghy N, Janbakhsh B. Insecticide resistance of Anopheles stephensi mysorensis in the province of Fars, southern Iran. Mosq News. 1976;36:336-9.

16. Manouchehri A, Zaini A, Yazdanpanah H. Selection for resistance to malathion in Anopheles stephensi mysorensis. Mosq News. 1975:35:278-80.

17. Manouchehri A, Zaini A, Djanbakhsh B. Preliminary note on the resistance of Anopheles stephensi to malathion in Bandar Abbas, southern Iran. Mosq News. 1976;36:207-8.

18. Yaghoobi-Ershadi M, Manouchehri A. Malaria and Hormozgan province. J Sch Med. 1986;3-4:69-79.

19. Iranpour M, Yaghobi Ershadi M, Motabar M. Susceptibility to organochlorine, organophophorous, carbamate and pyrethroid insecticides of Anopheles stephensi from Minab. Iran J Public Health. 1994;2:87-98.

20. Mousa-Kazemi S, Yaghobi Ershadi M. Comparison of susceptibility level of wild population of Anopheles stephensi to insecticides in Minab and Bandarabbas. J Birjand Uni Med Sci. 1998:5:32-9.

21. Peffly R. Insecticide resistance in anophelines in eastern Saudi Arabia. Bull World Health Organ. 1959:20:757-76.

22. Davidson G, Jackson CE. DDT-resistance in Anopheles stephensi. Bull World Health Organ. 1961;25:209-17.

23. Gramiccia G, De Meillon B, Petrides J, Ulrich A. Resistance to DDT in Anopheles stephensi in southern Iraq. Bull World Health Organ. 1958:19:1102-4.

24. WHO. Insecticide resistance in Anopheles stephensi in Iraq: at the end of 1967. WHONBC.1968; 78:1-12.

25. Barwa C. Status of insecticide susceptibility in Afghanistan. General Directorate of Preventive Medicine and Primary Health Care CDD, National Malaria and Leishmaniasis Control Programme; Afghanistan; Ministry of Public Health, Islamic Republic of Afghanistan. 2011.

26. Ahmad M, Buhler C, Pignatelli P, Ranson H, Nahzat SM, Naseem M, et al. Status of insecticide resistance in high-risk malaria provinces in Afghanistan. Malar J. 2016;15:98.

27. Safi NHZ, Ahmadi AA, Nahzat S, Ziapour SP, Nikookar SH, Fazeli-Dinan $M$, et al. Evidence of metabolic mechanisms playing a role in multiple insecticides resistance in Anopheles stephensi populations from Afghanistan. Malar J. 2017:16:100 
28. Safi NHZ, Ahmadi AA, Nahzat S, Warusavithana S, Safi N, Valadan R, et al. Status of insecticide resistance and its biochemical and molecular mechanisms in Anopheles stephensi (Diptera: Culicidae) from Afghanistan. Malar J. 2019;18:249.

29. Rana SM, Khan EA, Yaqoob A, Latif AA, Abbasi MM. Susceptibility and irritability of adult forms of main malaria vectors against insecticides used in the indoor residual sprays in Muzaffargarh district, Pakistan: a field survey. J Med Entomol. 2014;51:387-91.

30. Ali Khan HA, Akram W, Lee S. Resistance to selected pyrethroid insecticides in the malaria mosquito, Anopheles stephensi (Diptera: Culicidae), from Punjab, Pakistan. J Med Entomol. 2018;55:735-8.

31. Singh RK, Kumar G, Mittal PK. Insecticide susceptibility status of malaria vectors in India: a review. Int J Mosq Res. 2014;1:5-9.

32. Chitra S, Pillai M. Development of organophosphorus and carbamateresistance in Indian strains of Anopheles stephensi Liston. Proc Anim Sci. 1984;93:159-70.

33. Dykes CL, Das MK, Eapen A, Batra CP, Ghosh SK, Vijayan VA, et al. Knockdown resistance (kdr) mutations in Indian Anopheles stephensi (Diptera: Culicidae) populations. J Med Entomol. 2016;53:315-20.

34. Ganesh K, Vijayan V, Urmila J, Gopalan N, Prakash S. Role of esterases and monooxygenase in the deltamethrin resistance in Anopheles stephensi Liston (1908), at Mysore. Indian J Exp Biol. 2002;40:583-8.

35. Gayathri V, Balakrishna Murthy P. Reduced susceptibility to deltamethrin and $k d r$ mutation in Anopheles stephensi Liston, a malaria vector in India. J Am Mosq Control Assoc. 2006;22:678-88.

36. Hariprasad TP, Shetty NJ. Biochemical basis of alphamethrin resistance in different life stages of Anopheles stephensi strains of Bangalore, India. Pest Manag Sci. 2016;72:1689-701.

37. Rajagopalan N, Vedamanikkam J, Ramoo H. A preliminary note on the development of resistance to DDT by larvae of Anopheles stephensi type in Erode Urban, South India. Bull Nat Soc India Malar Mosq Borne Dis. 1956:4:126-8

38. Singh OP, Dykes $C L$, Das MK, Pradhan $S$, Bhatt RM, Agrawal OP, et al. Presence of two alternative kdr-like mutations, L1014F and L1014S,

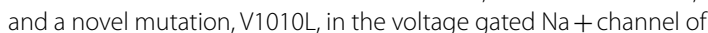
Anopheles culicifacies from Orissa, India. Malar J. 2010;9:67.

39. Singh OP, Dykes $C L$, Lather M, Agrawal OP, Adak T. Knockdown resistance ( $k d r$-like mutations in the voltage-gated sodium channel of a malaria vector Anopheles stephensi and PCR assays for their detection. Malar J. 2011;10:59.

40. Tikar S, Mendki M, Sharma A, Sukumaran D, Veer V, Prakash S, et al. Resistance status of the malaria vector mosquitoes, Anopheles stephensi and Anopheles subpictus towards adulticides and larvicides in arid and semi-arid areas of India. J Insect Sci. 2011;11:85.

41. Tiwari S, Ghosh SK, Ojha VP, Dash AP, Raghavendra K. Reduced susceptibility to selected synthetic pyrethroids in urban malaria vector Anopheles stephensi: a case study in Mangalore city, South India. Malar J. 2010;9:179.

42. Riveron JM, Tchouakui M, Mugenzi L, Menze BD, Chiang M-C, Wondji $\mathrm{CS}$. Insecticide resistance in malaria vectors: an update at a global scale. In: Manguin S, Vas D, editors. Towards malaria elimination-a leap forward. New York: Intech Open; 2018. p. 149-75.

43. Enayati AA, Ranson H, Hemingway J. Insect glutathione transferases and insecticide resistance. Insect Mol Biol. 2005;14:3-8.

44. Hemingway J. The molecular basis of two contrasting metabolic mechanisms of insecticide resistance. Insect Biochem Mol Biol. 2000;30:1009-15.

45. Hemingway J, Ranson $\mathrm{H}$. Insecticide resistance in insect vectors of human disease. Ann Rev Ent. 2000;45:369-89.

46. Vontas JG, Small GJ, Hemingway J. Glutathione S-transferases as antioxidant defence agents confer pyrethroid resistance in Nilaparvata lugens. Biochem J. 2001;357:65-72.

47. Ganesh KN, Urmila J, Vijayan VA. Pyrethroid susceptibility \& enzyme activity in two malaria vectors, Anopheles stephensi (Liston) \& A. culicifacies (Giles) from Mysore, India. Indian J Med Res. 2003;1 17:30-8.

48. Singh OP, Bali P, Hemingway J, Subbarao SK, Dash AP, Adak T. PCR-based methods for the detection of L1014 kdr mutation in Anopheles culicifacies sensu lato. Malar J. 2009:8:154

49. Dharmasiri AG, Perera AY, Harishchandra J, Herath $H$, Aravindan $\mathrm{K}$, Jayasooriya H, et al. First record of Anopheles stephensi in Sri Lanka: a potential challenge for prevention of malaria reintroduction. Malar J. 2017;16:326.

50. Carter TE, Yared S, Gebresilassie A, Bonnell V, Damodaran L, Lopez K, et al. First detection of Anopheles stephensi Liston, 1901 (Diptera: culicidae) in Ethiopia using molecular and morphological approaches. Acta Trop. 2018;188:180-6.

51. Faulde MK, Rueda LM, Khaireh BA. First record of the Asian malaria vector Anopheles stephensi and its possible role in the resurgence of malaria in Djibouti, Horn of Africa. Acta Trop. 2014:139:39-43.

52. WHO. WHO malaria policy advisory committee (MPAC) meeting: meeting report. Geneva: World Health Organization; 2019. p. 23.

53. Seyfarth M, Khaireh BA, Abdi AA, Bouh SM, Faulde MK. Five years following first detection of Anopheles stephensi (Diptera: Culicidae) in Djibouti, Horn of Africa: populations established-malaria emerging. Parasitol Res. 2019;118:725-32.

54. Yared S, Gebressielasie A, Damodaran L, Bonnell V, Karen L, Janies D, et al. Insecticide resistance in Anopheles stephensi in Somali Region, eastern Ethiopia. Malar J. 2020;19:180.

55. Surendran SN, Sivabalakrishnan K, Sivasingham A, Jayadas TT, Karvannan K, Santhirasegaram S, et al. Anthropogenic factors driving recent range expansion of the malaria vector Anopheles stephensi. Front Public Health. 2019;7:53.

56. WHO. Global plan for insecticide resistance management in malaria vectors (GPIRM). Geneva: World Health Organization; 2012. p. 132.

57. WHO. Test procedures for insecticide resistance monitoring in malaria vector mosquitoes. Geneva, World Health Organization. 2016: 48.

58. Eshghy N, Ladoni H, Javadian E. Resistance of Anopheles stephensi Liston to malathion in the provice of Fars, Southern Iran. Iran J Public Health. 1985;14:1-8.

59. Vatandoost N, Borhani N. Susceptibility and irritability levels of main malaria vectors to synthetic pyrethroids in the endemic areas of Iran. Acta Med Iran. 2004;42:240-7.

60. Vatandoost H, Mashayekhi M, Abaie M, Aflatoonian M, Hanafi-Bojd A, Sharifi I. Monitoring of insecticides resistance in main malaria vectors in a malarious area of Kahnooj district, Kerman province, southeastern Iran. JVector Borne Dis. 2005:42:100-8.

61. Vatandoost H, Oshaghi M, Abaie M, Shahi M, Yaaghoobi F, Baghaii M, et al. Bionomics of Anopheles stephensi Liston in the malarious area of Hormozgan province, southern Iran, 2002. Acta Trop. 2006;97:196-203.

62. Djadid ND, Barjesteh H, Raeisi A, Hassanzahi A, Zakeri S. Identification, sequence analysis, and comparative study on GSTe2 insecticide resistance gene in three main world malaria vectors: Anopheles stephensi, Anopheles culicifacies, and Anopheles fluviatilis. J Med Entomol. 2006:43:1171-7.

63. Abai M, Mehravaran A, Vatandoost H, Oshaghi M, Javadian E, Mashayekhi $\mathrm{M}$, et al. Comparative performance of imagicides on Anopheles stephensi, main malaria vector in a malarious area, southern Iran. J Vector Borne Dis. 2008;45:307-12.

64. Azizi K, Soltani A, Poodat A, Khodadadi M, Yaran M, Hasanvand B. Susceptibility of Anopheles stephensi against five current chemical insecticides. Hormozgan Med J. 2011;14:305-11.

65. Hanafi-Bojd A, Vatandoost H, Philip E, Stepanova E, Abdi A, Safari R, et al. Malaria situation analysis and stratification in Bandar Abbas County, southern Iran, 2004-2008. Iran J Arthropod Borne Dis. 2010;4:31-41.

66. Soleimani Ahmadi M, Vatandoost H, Shaeghi M, Raeisi A, Abedi F, Eshraghian $\mathrm{M}$, et al. Vector ecology and susceptibility in a malariaendemic focus in southern Islamic Republic of Iran. E Mediterr Health J. 2012;18:1034-41.

67. Vatandoost $\mathrm{H}$, Hanafi-Bojd AA. Indication of pyrethroid resistance in the main malaria vector, Anopheles stephensi from Iran. Asian Pac J Trop Med. 2012;5:722-6.

68. Hanafi-Bojd A, Vatandoost H, Oshaghi M, Haghdoost A, Shahi M, Sedaghat M, et al. Entomological and epidemiological attributes for malaria transmission and implementation of vector control in southern Iran. Acta Trop. 2012;121:85-92.

69. Yeryan M, Basseri HR, Hanafi-Bojd AA, Raeisi A, Edalat H, Safari R. Bioecology of malaria vectors in an endemic area, Southeast of Iran. Asian Pac J Trop Med. 2016;9:32-8.

70. Gorouhi MA, Vatandoost H, Oshaghi MA, Raeisi A, Enayati AA, Mirhendi $\mathrm{H}$, et al. Current susceptibility status of Anopheles stephensi (Diptera: 
Culicidae) to different imagicides in a malarious area, southeastern of Iran. J Arthropod borne Dis. 2016;10:493-500.

71. Zare M, Soleimani-Ahmadi M, Davoodi SH, Sanei-Dehkordi A. Insecticide susceptibility of Anopheles stephensi to DDT and current insecticides in an elimination area in Iran. Parasit Vectors. 2016;9:571.

72. Fathian M, Vatandoost H, Moosa-Kazemi SH, Raeisi A, Yaghoobi-Ershadi MR, Oshaghi MA, et al. Susceptibility of Culicidae mosquitoes to some insecticides recommended by WHO in a malaria endemic area of southeastern Iran. J Arthropod Borne Dis. 2015;9:22-34

73. Zaim M. Malaria control in Iran-present and future. J Am Mosq Control Assoc. 1987:3:392-6.

74. Vatandoost H, Shahi H, Abai M, Hanafi-Bojd A, Oshaghi M, Zamani G. Larval habitats of main malaria vectors in Hormozgan province and their susceptibility to different larvicides. Southeast Asian J Trop Med Public Health. 2004;35:22-5.

75. Abbasi M, Hanafi-Bojd AA, Yaghoobi-Ershadi MR, Vatandoost H, Oshaghi MA, Hazratian T, et al. Resistance status of main malaria vector, Anopheles stephensi Liston (Diptera: Culicidae) to insecticides in a malaria Endemic Area, Southern Iran. Asian Pac J Trop Med. 2019;12:43-8.

76. Vatandoost H, Abai MR, Akbari M, Raeisi A, Yousefi H, Sheikhi S, et al. Comparison of CDC bottle bioassay with WHO standard method for assessment susceptibility level of malaria vector, Anopheles stephensi to three imagicides. J Arthropod Borne Dis. 2019;13:17-26.

77. Shahi M, Hanafi-Bojd A, Vatandoost H, Soleimani Ahmadi M. Susceptibility status of Anopheles stephensi liston the main malaria vector, to deltamethrin and Bacillus thuringiensis in the endemic malarious area of Hormozgan province, southern Iran. J Kerman Uni Med Sci. 2012;20:87-95.

78. Nikpour F, Vatandoost H, Hanafi-Bojd AA, Raeisi A, Ranjbar M, Enayati $A A$, et al. Evaluation of deltamethrin in combination of piperonyl butoxide (PBO) against pyrethroid resistant, malaria vector, Anopheles stephensi in IRS implementation: an experimental semi-filed trial in Iran. Iran J Arthropod Borne Dis. 2017;11:469-81.

79. WHO: Malaria Threat Map. https://apps.who.int/malaria/maps/threats. Accessed 18 Jun 202.

80. Hemingway J. Genetics and biochemistry of insecticide resistance in Anophelines. PhD thesis, London School of Hygiene \& Tropical Medicine, 1981. https://doi.org/10.17037/pubs.04609913.

81. Rathor HR, Nadeem G, Khan IA. Pesticide susceptibility status of Anopheles mosquitoes in four flood-affected districts of South Punjab, Pakistan. Vector Borne Zoonotic Dis. 2013;13:60-6.

82. WHO. Global report on insecticide resistance in malaria vectors: 2010-2016. Geneva: World Health Organization; 2018. p. 72.

83. Kumari R, Thapar B, Das RG, Kaul S, Lal S. Susceptibility status of malaria vectors to insecticides in India. J Commun Dis. 1998;30:179-85.

84. Enayati AA. Cross resistance between DDT and permethrin in Anopheles stephensi from Iran. MSc thesis. Tarbiat Modarress University. Tehran. 1992.

85. Omer SM, Georghiou GP, Irving SN. DDT/pyrethroid resistance interrelationships in Anopheles stephensi. Mosq News. 1980;40:200-9.

86. Davari B, Vatandoost H, Oshaghi M, Ladonni H, Enayati A, Shaeghi M, et al. Selection of Anopheles stephensi with DDT and dieldrin and crossresistance spectrum to pyrethroids and fipronil. Pestic Biochem Physiol. 2007;89:97-103.

87. Soltani A, Vatandoost H, Oshaghi MA, Ravasan NM, Enayati AA, Asgarian F. Resistance mechanisms of Anopheles stephensi (Diptera: Culicidae) to temephos. J Arthropod Borne Dis. 2015;9:71-83.

88. Soltani A, Vatandoost H, Oshaghi MA, Enayati AA, Chavshin AR. The role of midgut symbiotic bacteria in resistance of Anopheles stephensi (Diptera: Culicidae) to organophosphate insecticides. Pathog Glob Health. 2017;111:289-96.

89. Gorouhi MA, Oshaghi MA, Vatandoost H, Enayati AA, Raeisi A, Abai MR, et al. Biochemical basis of cyfluthrin and DDT resistance in Anopheles stephensi (Diptera: Culicidae) in malarious area of Iran. J Arthropod Borne Dis. 2018;12:310-20.

90. Hemingway J. The biochemical nature of malathion resistance in Anopheles stephensi from Pakistan. Pestic Biochem Physiol. 1982;17:149-55.

91. Scott J, Georghiou G. Malathion-specific resistance in Anopheles stephensi from Pakistan. J Am Mosq Control Assoc. 1986;2:29-32.
92. van den Berg H, Zaim M, Yadav RS, Soares A, Ameneshewa B, Mnzava $A$, et al. Global trends in the use of insecticides to control vectorborne diseases. Environ Health Perspec. 2012;120:577-82.

93. WHO. Regional plan of action 2019-2023 for implementation of the global vector control response 2017-2030. World Health Organization. Regional Office for the Eastern Mediterranean. 2019:23.

94. WHO. Framework for a national plan for monitoring and management of insecticide resistance in malaria vectors. Geneva: World Health Organization; 2017. p. 39.

95. WHO. Global vector control response 2017-2030. Geneva: World Health Organization; 2017. p. 64.

96. Kelly-Hope L, Ranson H, Hemingway J. Lessons from the past: managing insecticide resistance in malaria control and eradication programmes. Lancet Infect Dis. 2008;8:387-9.

97. WHO. Malaria surveillance, monitoring \& evaluation: a reference manual. Geneva: World Health Organization; 2018. p. 206.

98. Sharp BL, Kleinschmidt I, Streat E, Maharaj R, Barnes KI, Durrheim $\mathrm{DN}$, et al. Seven years of regional malaria control collaborationMozambique, South Africa, and Swaziland. Am J Trop Med Hyg. 2007:76:42-7.

99. Coetzee M, Horne DWK, Brookea BD, Hunt RH. DDT, dieldrin and pyrethrold Insecticide resistance in African malaria vector mosquitoes: an historical review and implications for future malaria control in southern Africa. S Afr J Sci. 1999;95:215-8.

100. Lumjuan N, Rajatileka S, Changsom D, Wicheer J, Leelapat P, Prapanthadara $L-A$, et al. The role of the Aedes aegypti Epsilon glutathione transferases in conferring resistance to DDT and pyrethroid insecticides. Insect Biochem Mol Biol. 2011;41:203-9.

101. Paton MG, Karunaratne S, Giakoumaki E, Roberts N, Hemingway J. Quantitative analysis of gene amplification in insecticide-resistant Culex mosquitoes. Biochem J. 2000;346:17-24.

102. Prasad KM, Raghavendra K, Verma V, Velamuri PS, Pande V. Esterases are responsible for malathion resistance in Anopheles stephensi: A proof using biochemical and insecticide inhibition studies. J Vector Borne Dis. 2017:54:226-32.

103. Enayati AA, Vatandoost $\mathrm{H}$, Ladonni $\mathrm{H}$, Townson $\mathrm{H}$, Hemingway J. Molecular evidence for a kdr-like pyrethroid resistance mechanism in the malaria vector mosquito Anopheles stephensi. Med Vet Entomol. 2003;17:138-44.

104. Ranson H, Jensen B, Vulule J, Wang X, Hemingway J, Collins F. Identification of a point mutation in the voltage-gated sodium channel gene of Kenyan Anopheles gambiae associated with resistance to DDT and pyrethroids. Insect Mol Biol. 2000;9:491-7.

105. Reimer L, Fondjo E, Patchoké S, Diallo B, Lee Y, Ng A, et al. Relationship Between kdr mutation and resistance to pyrethroid and DDT insecticides in natural populations of Anopheles gambiae. J Med Entomol. 2008:45:260-6.

106. Singh O, Dykes C, Adak T. kdr-like mutations in the voltage gated sodium channel of a malaria vector Anopheles stephensi and development of PCR-based assays for their detection. Malar J. 2010;9:1.

107. Darriet F, Guillet P, Guessan RNN, Doannio JMC, Koffi AA, Konan $L Y$, et al. The impact of permethrin and deltamethrin resistance in Anopheles gambiaess on the efficacy of insecticide-treated mosquito nets (in French). Med Trop (Mars). 1998;58:349-54.

108. Darriet F, N'Guessan R, Koffi AA, Konan L, Doannio JM, Chandre F, et al. Impact of pyrethrin resistance on the efficacity of impregnated mosquito nets in the prevention of malaria: results of tests in experimental cases with deltamethrin SC (in French). Bull Soc Pathol Exot. 2000;93:131-4.

109. Darriet F, Robert V, Thovein N, Carnevalle P. Evaluation of the efficacy of permethrin-impregnated intact and perforated mosquito nets against vectors of malaria. WHO/NBC. 1984;84:899.

110. Henry MC, Assi SB, Rogier C, Dossou-Yovo J, Chandre F, Guillet P, et al. Protective efficacy of lambda-cyhalothrin treated nets in Anopheles gambiae pyrethroid resistance areas of Côte d'Ivoire. Am J Trop Med Hyg. 2005;73:859-64.

111. Henry MC, Doannio JM, Darriet F, Nzeyimana I, Carnevale P. Efficacy of permethrin-impregnated Olyset Net mosquito nets in a zone with pyrethroid resistance vectors II Parasitic and clinical evaluation (in French). Med Trop (Mars). 1999;59:355-7. 
112. N'Guessan R, Corbel V, Akogbéto M, Rowland M. Reduced efficacy of insecticide-treated nets and indoor residual spraying for malaria control in pyrethroid resistance area, Benin. Emerg Infect Dis. 2007;13:199-206.

113. Strode C, Donegan S, Garner P, Enayati AA, Hemingway J. The impact of pyrethroid resistance on the efficacy of insecticide-treated bed nets against African anopheline mosquitoes: systematic review and metaanalysis. PLoS Med. 2014;11:e1001619.

114. Hemingway J. Field and laboratory manual for the mechanistic detection of insecticide resistance in insects. Geneva: World Health Organization; 1998; WHO-CTD/MAL/986: 35.

115. Enayati AA, Ladonni H. Biochemical assays baseline data of permethrin resistance in Anopheles stephensi (Diptera, Culicidae) from Iran. Pakistan J Biol Sci. 2006;9:1265-70.

116. Bigoga JD, Ndangoh DN, Awono-Ambene PH, Patchoke S, Fondjo E, Leke RGF. Pyrethroid resistance in Anopheles gambiae from the rubber cultivated area of Niete, South Region of Cameroon. Acta Trop. 2012;124:210-4.

117. Hien AS, Soma DD, Hema O, Bayili B, Namountougou M, Gnankiné O, et al. Evidence that agricultural use of pesticides selects pyrethroid resistance within Anopheles gambiae s.l. populations from cotton growing areas in Burkina Faso, West Africa. PLoS ONE. 2017;12:e0173098.

118. Nkya TE, Poupardin R, Laporte F, Akhouayri I, Mosha F, Magesa S, et al. Impact of agriculture on the selection of insecticide resistance in the malaria vector Anopheles gambiae: a multigenerational study in controlled conditions. Parasit Vectors. 2014;7:480.

119. Yadouleton A, Martin T, Padonou G, Chandre F, Asidi A, Djogbenou L, et al. Cotton pest management practices and the selection of pyrethroid resistance in Anopheles gambiae population in Northern Benin. Parasit Vectors. 2011;4:60.

120. Yadouleton AWM, Asidi A, Djouaka RF, Brama J, Agossou CD, Akogbeto $M C$. Development of vegetable farming: a cause of the emergence of insecticide resistance in populations of Anopheles gambiae in urban areas of Benin. Malar J. 2009;8:103.

121. Oxborough RM, Kitau J, Jones R, Feston E, Matowo J, Mosha FW, et al. Long-lasting control of Anopheles arabiensis by a single spray application of micro-encapsulated pirimiphos-methyl (Actellic ${ }^{\circledR} 300$ CS). Malar J. 2014;13:37.

122. Zaim M, Aitio A, Nakashima N. Safety of pyrethroid-treated mosquito nets. Med Vet Entomol. 2000;14:1-5.

123. Zaim M, Guillet P. Alternative insecticides: an urgent need. Trends Parasitol. 2002;18:161-3.

124. Sahu SS, Thankachy S, Dash S, Nallan K, Swaminathan S, Kasinathan G, et al. Evaluation of long-lasting indoor residual spraying of deltamethrin 62.5 SC-PE against malaria vectors in India. Malar J. 2020;19:19.

125. Toe KH, Müller P, Badolo A, Traore A, Sagnon N, Dabiré RK, et al. Do bednets including piperonyl butoxide offer additional protection against populations of Anopheles gambiae s.l.s that are highly resistant to pyrethroids? An experimental hut evaluation in Burkina Faso. Med Vet Entomol. 2018;32:407-16.

126. Tungu P, Magesa S, Maxwell C, Malima R, Masue D, Sudi W, et al. Evaluation of Permanet 3.0 a deltamethrin-PBO combination net against Anopheles gambiae and pyrethroid resistant Culex quinquefasciatus mosquitoes: An experimental hut trial in Tanzania. Malar J. 2010;9:21.

127. Allossogbe M, Gnanguenon V, Yovogan B, Akinro B, Anagonou R, Agossa F, et al. WHO cone bio-assays of classical and new-generation long-lasting insecticidal nets call for innovative insecticides targeting the knock-down resistance mechanism in Benin. Malar J. 2017;16:77.

\section{Publisher's Note}

Springer Nature remains neutral with regard to jurisdictional claims in published maps and institutional affiliations.
Ready to submit your research? Choose BMC and benefit from:

- fast, convenient online submission

- thorough peer review by experienced researchers in your field

- rapid publication on acceptance

- support for research data, including large and complex data types

- gold Open Access which fosters wider collaboration and increased citations

- maximum visibility for your research: over 100M website views per year

At BMC, research is always in progress.

Learn more biomedcentral.com/submissions 